\title{
A High-Precision Passive Air Sampler for Gaseous Mercury
}

\author{
David S. McLagan, ${ }^{\dagger}$ Carl P. J. Mitchell, ${ }^{\dagger}$ Haiyong Huang, ${ }^{\dagger}$ Ying Duan Lei, ${ }^{\dagger}$ Amanda S. Cole, ${ }^{\dagger}$ \\ Alexandra Steffen, ${ }^{*}$ Hayley Hung, ${ }^{\ddagger}$ and Frank Wania* ${ }^{\dagger}$
}

${ }^{\dagger}$ Department of Physical and Environmental Sciences, University of Toronto Scarborough, 1265 Military Trail, Toronto, ON M1C 1A4, Canada

${ }^{\ddagger}$ Air Quality Processes Research Section, Environment Canada, 4905 Dufferin Street, North York, ON M3H 5T4, Canada

\section{Supporting Information}

ABSTRACT: Passive air samplers (PASs) provide an opportunity to improve the spatial range and resolution of gaseous mercury $(\mathrm{Hg})$ measurements. Here, we propose a sampler design that combines a sulfurimpregnated activated carbon sorbent, a Radiello diffusive barrier, and a protective shield for outdoor deployments. The amount of gaseous $\mathrm{Hg}$ taken up by the sampler increased linearly with time for both an 11-week indoor $\left(r^{2}\right.$ $=0.990)$ and 12-month outdoor $\left(r^{2}=0.996\right)$ deployment, yielding sampling rates of $0.158 \pm 0.008 \mathrm{~m}^{3}$ day $^{-1}$ indoors and $0.121 \pm 0.005 \mathrm{~m}^{3}$ day $^{-1}$ outdoors. These sampling rates are close to modeled estimates of $0.166 \mathrm{~m}^{3}$ day ${ }^{-1}$ indoors and $0.129 \mathrm{~m}^{3}$ day $^{-1}$ outdoors. Replicate precision is better than for all previous PASs for gaseous $\mathrm{Hg}$, especially during outdoor deployments $(2 \pm 1.3 \%)$. Such precision is essential for discriminating the relatively small concentration variations occurring at background sites. Deployment times for

obtaining reliable time-averaged atmospheric gaseous $\mathrm{Hg}$ concentrations range from a week to at least one year.

\section{INTRODUCTION}

Atmospheric mercury $(\mathrm{Hg})$ can be found in three forms: gaseous elemental $\mathrm{Hg}$ (GEM), gaseous oxidized $\mathrm{Hg}$ (GOM), and particle-bound $\mathrm{Hg}$. The most persistent of these atmospheric forms is GEM (atmospheric residence time of $\sim 1$ year). ${ }^{1-3}$ As such, long-range atmospheric transport of GEM is the primary mechanism for distributing $\mathrm{Hg}$ globally. ${ }^{1,4}$ GEM typically makes up $>95 \%$ of total gaseous $\mathrm{Hg}$ (TGM, consisting of GEM and GOM) at most sampling locations. ${ }^{5-7}$ Coastal polar sites during springtime are an exception, as rapid oxidation of GEM to GOM during atmospheric $\mathrm{Hg}$ depletion events (AMDEs) can cause GOM to contribute up to $100 \%$ of TGM for short periods of time (hours to days). ${ }^{8}$ Recently, Gustin et al. hypothesized that uncertainties associated with some GEM, GOM, and/or TGM measurements suggest that GOM may contribute up to $25 \%$ of TGM at both inland and coastal sites in the United States. ${ }^{9}$ Empirical confirmation through actual measurements of elevated GOM concentrations relative to concurrently measured GEM concentrations will be required to substantiate this hypothesis. In the meantime, we use the term gaseous $\mathrm{Hg}$ when it is uncertain whether a measurement records GEM or TGM concentrations.

Mean annual gaseous $\mathrm{Hg}$ concentrations at remote background sites range from 1.5 to $1.7 \mathrm{ng} \mathrm{m}^{-3}$ and from 1.1 to 1.3 $\mathrm{ng} \mathrm{m}^{-3}$ in the Northern and Southern hemispheres, respectively, ${ }^{10,11}$ with significantly higher concentrations in areas impacted by but distant from point sources. ${ }^{12-14}$ Given that these long-term average concentrations typically vary within a fairly narrow range $\left(<0.5 \mathrm{ng} \mathrm{m}^{-3}\right.$ at remote

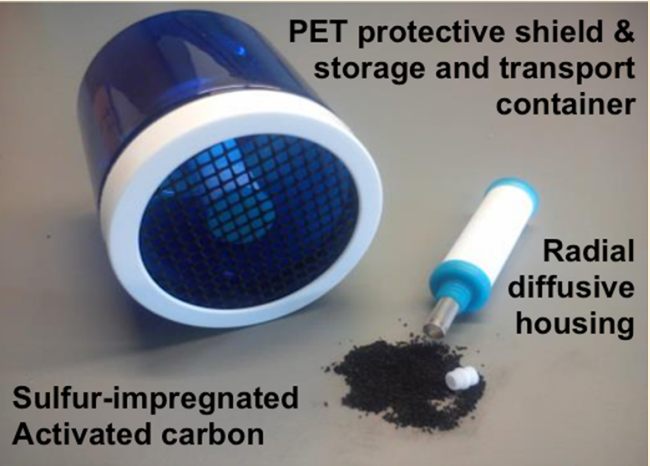

background sites and a few nanograms per cubic meter at background sites within source regions), ${ }^{10}$ atmospheric gaseous $\mathrm{Hg}$ monitoring seeking to discriminate such differences needs to be very precise. ${ }^{10,15}$ The recent introduction of the Minamata Convention to reduce global $\mathrm{Hg}$ emissions will require precise, long-term monitoring of $\mathrm{Hg}$ across the globe to assess its effectiveness. ${ }^{16}$

The current spatial resolution and range of global gaseous $\mathrm{Hg}$ concentration data are limited because of high costs associated with instruments, energy and gas, and the technical training requirements needed for automated monitoring techniques. ${ }^{11,15,17}$ While not able to produce data at the same fine temporal resolution as the automated techniques, passive air samplers (PASs) that require no electrical energy, are low cost, and are easy to deploy have the potential to substantially improve the spatial resolution of gaseous $\mathrm{Hg}$ data. ${ }^{15,17,18}$

Several PAS prototypes for gaseous $\mathrm{Hg}$ have been proposed over the years to meet the stated need for "a standard accurate calibrated passive sampling method". ${ }^{18}$ However, recent reviews concluded that their accuracy and precision are insufficient for long-term monitoring of gaseous $\mathrm{Hg}$ at sites removed from major atmospheric $\mathrm{Hg}$ sources. ${ }^{15,18}$ Here, we present a novel PAS design for precisely monitoring background concentrations of gaseous $\mathrm{Hg}$ across a wide range of effective

Received: November 17, 2015

Revised: December 18, 2015

Accepted: December 22, 2015

Published: December 22, 2015 
deployment times. We note that, as with many other sampling techniques, the exact species of gaseous $\mathrm{Hg}$ sampled by the PAS is uncertain. The use of a diffusive barrier in our sampler design will prevent sampling of particulate-bound $\mathrm{Hg}$. While the reactive nature of GOM is likely to prevent it too from passing through the diffusive barrier, this is yet to be proven.

\section{METHODS}

Passive Sampler Design. The PAS presented here combines elements of previously reported PASs for gaseous $\mathrm{Hg}$, namely, the use of (i) a commercially available, bituminous coal-derived, sulfur-impregnated activated carbon (HGR-AC) as the sorbent (product no. 2300, Calgon Carbon Corp.), ${ }^{19}$ (ii) radial diffusion through a microporous diffusive body to constrain the rate of sampling, ${ }^{10,20}$ and (iii) a protective shield to protect the sampler from wind and precipitation (Figure 1). ${ }^{10}$ Specifically, a mesh cylinder (stainless steel, height of 60

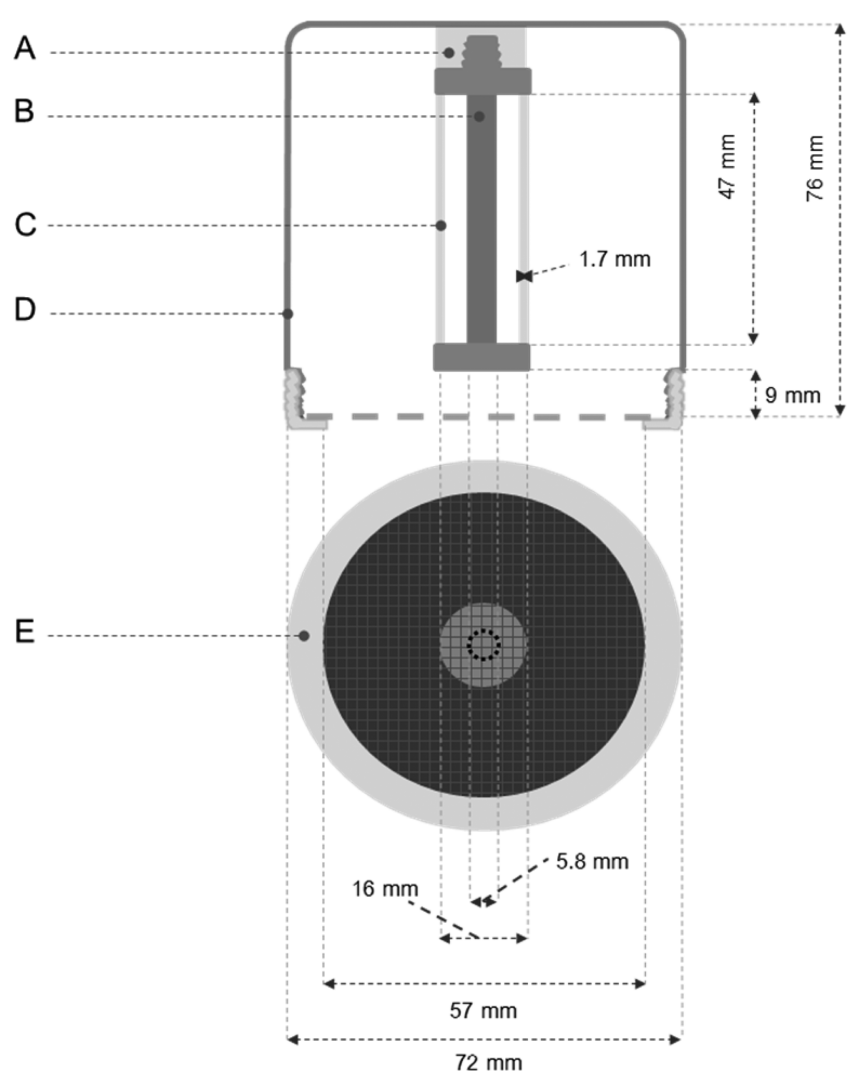

Figure 1. Technical drawing of a passive air sampler for monitoring gaseous Hg: (A) polytetrafluoroethylene screw cap, (B) stainless steel mesh cylinder containing HGR-AC sorbent, (C) microporous diffusive barrier made from high-density polyethylene, (D) protective shield made from polyethylene terephthalate, and (E) open polypropylene lid with a mesh screen, replaced with a closed lid for storage and transport. The diagram is to scale.

$\mathrm{mm}$, diameter of $5.8 \mathrm{~mm}$, mesh size of $165,47 \%$ open area, open at the top, closed at the bottom with a $0.1 \mathrm{~mm}$ stainless steel plate) is filled with $0.662 \pm 0.043 \mathrm{~g}$ of HGR-AC that has been crushed using a laboratory grinder and sieved to a mesh size of $25 \times 50$ (particle diameter of $300-710 \mu \mathrm{m}$ ). The open end of the cylinder is then capped with a polytetrafluoroethylene (PTFE) stopper and placed within a commercially available, white Radiello diffusive body (high-density polyethylene, porous section height of $47 \mathrm{~mm}$, porous barrier thickness of $1.7 \mathrm{~mm}$, diameter of $16 \mathrm{~mm}$ ). This diffusive body is then screwed into a PTFE cap, which in turn is glued to the interior of a polyethylene terephthalate (PET) jar (height of 75 $\mathrm{mm}$, diameter of $72 \mathrm{~mm}$ ). During deployment, a polypropylene (PP) lid fitted with a PP mesh screen (diamond openings, height of $5 \mathrm{~mm}$, width of $4 \mathrm{~mm}$ ) is used on the bottom of the jar to block entry of animals. Gaseous $\mathrm{Hg}$ enters the sampler, undergoing radial molecular diffusion through the diffusive barrier, through the internal airspace of the sampler, and into the sorbent.

Study Design. To derive sampling rates (SRs), Hg uptake in the sampler was measured for an 11-week period inside a laboratory and for a 12-month period in the field. The SR represents the volume of air that is effectively stripped of $\mathrm{Hg}$ per unit time. During both studies, gaseous $\mathrm{Hg}$ air concentrations were recorded at 5 min intervals using a Tekran $2537 \mathrm{~B}$ instrument with $2 \mathrm{~m}$ Teflon tubing connected to a 0.2 $\mu \mathrm{m}$ PTFE filter as the sampler inlet (details are given in ref 21). The Tekran 2537B instrument was calibrated at $25 \mathrm{~h}$ intervals using the internal $\mathrm{Hg}$ permeation source of the system. Manual $\mathrm{Hg}$ injections from an external $\mathrm{Hg}$ source were made before and after the experiments to verify calibrations.

During the indoor study, 33 samplers without a protective shield were deployed upright on a bench in a small laboratory. Three randomly selected replicates were removed weekly for 11 weeks. To prevent further $\mathrm{Hg}$ uptake after retrieval, the Radiello diffusive bodies were wrapped in PTFE tape and replicates were placed in a PP container, which was sealed with PTFE tape. Room ventilation as well as opening and closing of doors and movement of lab personnel will have generated some air turbulence in the vicinity of the samplers. However, wind speed, measured at the end of the study, was below the detection limit of the hotwire anemometer $\left(<0.1 \mathrm{~m} \mathrm{~s}^{-1}\right)$. The air temperature was $21-23{ }^{\circ} \mathrm{C}$ throughout the study.

For the outdoor study, 63 PASs were deployed on April 8, 2014 , at the University of Toronto Scarborough $\left(43.7836^{\circ} \mathrm{N}\right.$, $79.1856^{\circ} \mathrm{W}$ ). Samplers were placed $1.5 \mathrm{~m}$ above ground level by attaching them to a fence. Three randomly selected PASs were removed weekly for the first 12 weeks and then monthly for an additional 9 months. To prevent further $\mathrm{Hg}$ uptake, the open mesh lids were removed and exchanged for a solid PP lid, which was sealed, wrapped with PTFE tape, and stored in a resealable bag at room temperature. Wind speed, wind direction, and temperature were monitored during the year of deployment at a site on top of a nearby building $(\sim 10 \mathrm{~m}$ above ground level, $\sim 50 \mathrm{~m}$ away). Temperature and wind speed (averaged on an hourly basis) ranged from -25.9 to $29.7^{\circ} \mathrm{C}$ and from 0.1 to $6.7 \mathrm{~m} \mathrm{~s}^{-1}$, respectively.

Total $\mathrm{Hg}$ concentrations in the HGR-AC were determined by thermal desorption, amalgamation, and atomic absorption spectroscopy (USEPA Method 7473) ${ }^{22}$ using a DMA-80 instrument (Milestone Inc.; see SI1 for details of instrumental parameters, calibration setup, and QA/QC). Statistical tests were run using WinSTAT version 5.0 (WinSTAT, R. Fitch Software) with an $\alpha$ value of 0.05 in all tests.

Empirical Sampling Rate Determination. Restrepo et al. $^{23}$ discuss different approaches for deriving a SR (cubic meters per day). One method relies on the calculation of a SR for each individual PAS using

$$
\mathrm{SR}=m /(C t)
$$

where $m$ is the amount of analyte collected by the PAS (nanograms), $C$ is the mean actively measured concentration 

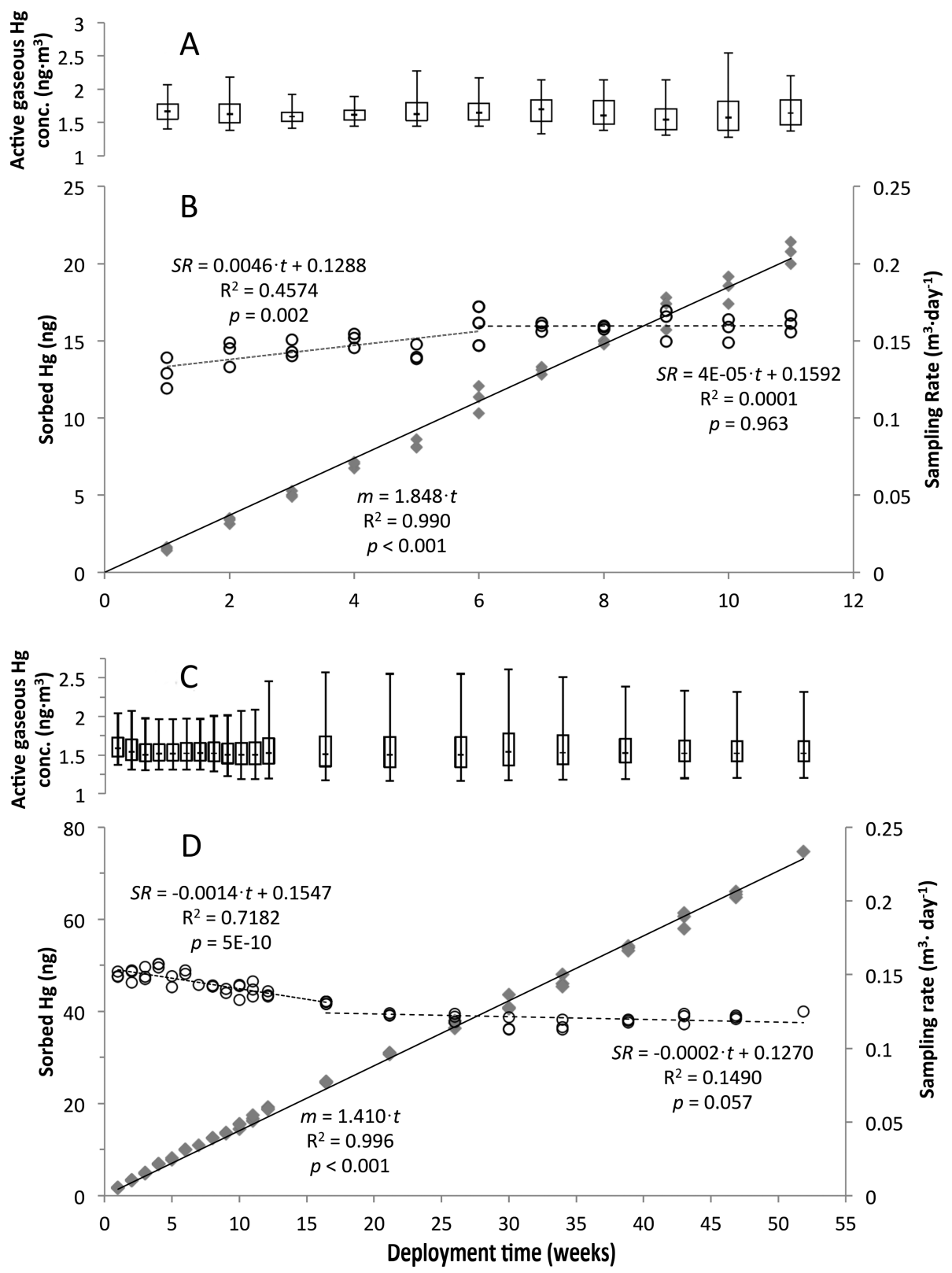

Figure 2. Uptake curve (solid diamonds, left axes) and SR (O, right axes) of individual samplers for indoor (B) and outdoor (D) uptake studies. Linear relationships between initial SRs and time were determined by sequentially eliminating weekly replicates until the linear fit was not significantly different from zero. From this point on, the sampling rate was considered stable. Actively measured gaseous $\mathrm{Hg}$ concentrations for each deployment period are given in panels $\mathrm{A}$ and $\mathrm{C}$ for the indoor and outdoor experiments, respectively. Whiskers represent 5th and 95th percentiles; the box represents 1st and 3rd quartiles, and the marker is the median of actively measured hourly averaged gaseous $\mathrm{Hg}$ data.

over the sampling period (nanograms per cubic meter), and $t$ is the deployment time (days). The overall SR is then the average of these individual SR values. Alternatively, eq 1 can be rewritten as $m=\mathrm{SR} \times C \times t$ and SR derived as the slope of a linear regression between $m$ and $C t$. Because all $\mathrm{Hg}$ concentrations in samples are blank-corrected (see SI1), the regression was forced through zero. The final reported values for the SRs were derived using this slope method that had a lower uncertainty (see SI2 for details).

Theoretical Sampling Rate Estimation. We also estimated the SR theoretically. Agreement between theoretical and empirical SRs is a prerequisite for claiming a quantitative understanding of the processes involved in the uptake of $\mathrm{Hg}$ in the PAS. The assumption underlying the theoretical estimation is that gaseous $\mathrm{Hg}$ must undergo three sequential molecular diffusion steps, through (i) an air-side boundary layer, (ii) the pore space of the diffusive barrier, and (iii) the internal air space of the Radiello. If we account for the radial geometry of each of these steps, the SR can be calculated as

$$
\begin{aligned}
\mathrm{SR}= & D(T, P) \times 2 \pi h /\left[\ln \left(r_{\mathrm{a}} / r_{\mathrm{d}-\text { out }}\right)+v^{-1.33}\right. \\
& \left.\times \ln \left(r_{\mathrm{d} \text {-out }} / r_{\mathrm{d} \text {-in }}\right)+\ln \left(r_{\mathrm{d} \text {-in }} / r_{\mathrm{s}}\right)\right]
\end{aligned}
$$

where $D(T, P)$ is the molecular diffusion coefficient of GEM (the dominant fraction of gaseous $\mathrm{Hg}$ ) in air (square meters per day), which is a function of temperature $T$ and pressure $P, h$ is the height of the diffusive barrier (meters), and $r_{\mathrm{a}}, r_{\mathrm{d}-\mathrm{out}}, r_{\mathrm{d}-\mathrm{in}}$, and $r_{\mathrm{s}}$ are the radii corresponding to the outside of the air-side boundary layer, the diffusive barrier, the internal air space, and the sorbent cylinder (meters), respectively. The term $v^{-1.33}$ 
accounts for the tortuous path through the porous diffusive barrier, with $v$ being the porosity (unitless). ${ }^{24}$ A porosity of $0.496 \pm 0.001$ for the Radiello diffusive barrier was determined via $\mathrm{Hg}$ intrusion porosimetry (Quantachrome Material Characterization Laboratory). A cross sectional diagram of this system is presented in SI3.

\section{RESULTS AND DISCUSSION}

Agreement between Replicates. Figure 2 shows the amount of sorbed $\mathrm{Hg}$ as a function of deployment time for both the indoor (panel B) and outdoor (panel D) studies. The mean relative standard deviation (RSD) of sorbed $\mathrm{Hg}$ between triplicate samplers was $4 \pm 2$ and $2 \pm 1 \%$ for the indoor and outdoor experiments, respectively. This replicate precision, in particular for the outdoor study, was considerably smaller than the RSDs reported for other PASs attempting to monitor background concentrations of gaseous $\mathrm{Hg}$. In other studies, the lowest mean RSDs between sampler replicates were reported to be $7.7 \%,{ }^{20}$ but more often, it was larger than $10 \%^{19,25}$ or not reported at all. ${ }^{10,26}$ The RSD was smaller for the PASs deployed outdoors, even though one might expect more stable conditions indoors. The smaller uncertainty outdoors is most likely related to the stabilizing influence of the protective shield, which was not used indoors. Furthermore, the effect of air turbulence on uptake is expected to be largest if that turbulence is low. ${ }^{20,27,28}$ For example, uptake of organic contaminants in a PAS was more variable indoors than outdoors, which was attributed to the greater sensitivity of SRs to wind at low wind speeds. ${ }^{29}$

Uptake Curves and Longest Deployment Times. The uptake curves (Figure 2) demonstrate the highly linear relationship between sorbed $\mathrm{Hg}$ and deployment time for both the indoor and outdoor studies $\left(R^{2}>0.99\right)$. This linearity indicates that the sorbent had not approached its equilibrium uptake capacity during deployment and that the variability on the time scale of weeks to months in the atmospheric concentration of gaseous $\mathrm{Hg}$ during deployment was very small. The latter is confirmed by the gaseous $\mathrm{Hg}$ concentration measured by the Tekran 2537B instrument. Over the course of the experiments, the range of daily average concentrations was $1.35-2.16 \mathrm{ng} \mathrm{m}^{-3}$ (mean of $1.65 \mathrm{ng} \mathrm{m}^{-3}$ ) indoors and 1.17$3.29 \mathrm{ng} \mathrm{m}^{-3}$ (mean of $1.68 \mathrm{ng} \mathrm{m}^{-3}$ ) outdoors (see SI4). Furthermore, the mean concentrations during each sampling period of all individual PASs were, as expected, even less variable [indoor range of $1.67-1.69 \mathrm{ng} \mathrm{m}^{-3}$, outdoor range of $1.55-1.71 \mathrm{ng} \mathrm{m}^{-3}$ (see also panels $\mathrm{A}$ and $\mathrm{C}$ of Figure 2, respectively, and SI4)]. The uncertainty of measurements with the Tekran 2537 systems has previously been estimated to be $5-10 \%{ }^{30}$ Given that there was no indication that uptake slowed toward the end of the 12-month outdoor experiment, the PAS can effectively be deployed to monitor gaseous $\mathrm{Hg}$ at background concentrations over time periods as long as at least one year.

Detection Limit, Quantification Limit, and Shortest Deployment Times. A method detection limit (MDL) for the PAS of $0.26 \mathrm{ng}$ of $\mathrm{Hg}$ was derived by multiplying 3 times the standard deviation of the field blank concentrations from both experiments $\left(0.51 \pm 0.13 \mathrm{ng} \mathrm{g}^{-1}\right)$ by the mean mass of HGRAC in each PAS $(0.662 \mathrm{~g})$. The method quantification limit (MQL) of $0.86 \mathrm{ng}$ of $\mathrm{Hg}$ was similarly derived using 10 times the standard deviation of the field blanks. Assuming a background gaseous $\mathrm{Hg}$ concentration of $1.5 \mathrm{ng} \mathrm{m}^{-3}$ and using the calibrated SRs listed below, this MDL translates to a minimal deployment time for the PAS of approximately 2 days.
On the basis of the MQL, deployments of approximately 5 days are advisable to ensure reliable quantification. At sites with elevated gaseous $\mathrm{Hg}$ concentrations, deployment times can, of course, be much shorter.

Empirically Determined Sampling Rates. When using the slope method, SRs of $0.158 \pm 0.008$ and $0.121 \pm 0.005 \mathrm{~m}^{3}$ day $^{-1}$ were obtained from the indoor and outdoor study, respectively. We suggest two key factors might have contributed to the lower SR observed outdoors: (i) the protective shield that added a kinetic resistance to $\mathrm{Hg}$ uptake in the sampler, presumably because reduced air turbulence inside the shelter increases the thickness of the stagnant boundary layer around the diffusive barrier, and (ii) the temperature dependence of the diffusivity coefficient for $\mathrm{Hg}$.

Figure 2 also displays the SRs calculated for each individual sampler using eq 1 as a function of deployment time (O). These data reveal that despite the strong linearity of the uptake curves, there was a slight increase in SRs during the first 6 weeks of the indoor experiment, whereas the SRs outdoors decreased during the first 16 weeks of the outdoor experiment. It is possible to envisage reasons why in the first period after deployment, SRs may deviate from the long-term average SR. For example, initially lower SRs could occur if gaseous $\mathrm{Hg}$ is sorbed to the HDPE of the diffusive barrier. Once gaseous $\mathrm{Hg}$ establishes an equilibrium between the HDPE and the gas phase, the SR would stabilize. An initially higher SR, sometimes termed a two-stage uptake mechanism in the literature, ${ }^{31,32}$ might occur if the gaseous $\mathrm{Hg}$ sorbs to sites at the outside of the carbon-filled cylinder first but then has to diffuse through the pores between and within the carbon particles to reach internal sorption sites. ${ }^{33}$ The latter would be consistent with reports that the rate-limiting step for removal of vapor phase $\mathrm{Hg}$ by HGR-AC in industrial applications was diffusion of $\mathrm{Hg}$ into internal binding sites once exterior binding sites became saturated. ${ }^{34}$ It is, however, difficult to explain why the former phenomena should occur indoors, while the latter outdoors.

After the first 6 weeks in the indoor experiment and after the first 4 months of outdoor deployment, the SRs were no longer dependent on deployment time; i.e., the slope of a linear regression between SR and $t$ was not significantly different from zero. The SRs derived from the slope method using only the data from weeks 6-11 (indoor) and months 4-12 (outdoor) were $0.160 \pm 0.006$ and $0.120 \pm 0.004 \mathrm{~m}^{3}$ day $^{-1}$, respectively. These values are within $1 \%$ of the SRs obtained when all data were included, suggesting that the initial deviations in the SRs have very little impact on the SR applicable over deployments lasting more than 1 or 2 months. For shorter deployments, it may be feasible to estimate deployment time specific SRs using the linear relationships included in Figure 2. However, for deployment at sites of elevated gaseous $\mathrm{Hg}$ concentrations, this is unlikely to be necessary, because faster uptake of gaseous $\mathrm{Hg}$ should shorten the time required for the SR to stabilize.

Theoretically Derived Sampling Rates. With the exception of $r_{a}$ all of the parameters in eq 2 are known or can be determined with a high degree of precision. When testing the performance of a model estimating SRs in a PAS for organic vapors, Armitage et al. ${ }^{35}$ obtained good agreement with empirical data when assuming an air-side boundary layer thickness of $10 \mathrm{~mm}$ (range of 7.5-15 mm). Adopting a similar range of values for $r_{\mathrm{a}}-r_{\mathrm{d} \text {-out }}$ and using a molecular diffusivity of gaseous $\mathrm{Hg}$ adjusted to either the indoor temperature $\left(22^{\circ} \mathrm{C}\right)$ or the average temperatures during the outdoor study (7.6 $\left.{ }^{\circ} \mathrm{C}\right),{ }^{36}$ we estimated the theoretical SR of the PAS to be 0.156 
$\mathrm{m}^{3}$ day $^{-1}$ indoors (range of $0.166-0.141 \mathrm{~m}^{3}$ day $^{-1}$ ) and 0.142 $\mathrm{m}^{3}$ day $^{-1}$ outdoors (range of $0.152-0.129 \mathrm{~m}^{3}$ day $^{-1}$ ). These values compare favorably with the SRs determined indoors $\left(0.158 \mathrm{~m}^{3}\right.$ day $\left.^{-1}\right)$ and outdoors $\left(0.121 \mathrm{~m}^{3}\right.$ day $\left.^{-1}\right)$ and in particular confirm that the lower SRs outdoors might be, in part, due to slower diffusion at lower temperatures. The remaining difference between outdoor and indoor SRs is likely due to a thicker air boundary layer around a diffusive barrier that is caused by the use of a protective shield.

Looking Forward. A major strength of this new sampler design is its low precision-based uncertainty, which will ensure that the uncertainty of gaseous $\mathrm{Hg}$ concentrations determined with this sampler depends on the variability of the SRs between deployments. Here we could show that SRs during two deployments under very different conditions deviate by only $23 \%$ from each other. Furthermore, we could explain most of that discrepancy. However, the experiments described here do not yet allow for a full assessment of the uncertainty of concentrations determined with this sampler because the actively measured air concentrations were used in the derivation of the SRs and can therefore not be used for comparison with air concentrations obtained from PAS data. Therefore, to determine the full variability of SRs expected in outdoor deployments and the extent to which this variability can be explained by our understanding of the uptake process, we are currently measuring uptake curves in PASs deployed at a number of sites with ongoing active sampling across a wide range of climatic conditions. This includes sampling sites where atmospheric $\mathrm{Hg}$ depletion events are known to occur, potentially allowing for a determination of whether the PAS also takes up GOM. In addition to testing the suitability of the design within a variety of environments, this will allow for a determination of the accuracy-based uncertainty. The relatively small difference in SRs observed between sheltered samplers deployed outdoors and unsheltered samplers deployed indoors suggests that at a minimum the samplers can reliably distinguish places with concentrations at background levels $\left(1.5 \mathrm{ng} / \mathrm{m}^{3}\right)$ from those that have only slightly elevated levels $\left(>3 \mathrm{ng} / \mathrm{m}^{3}\right)$. If it should be feasible to determine the coefficient of sorption of gaseous $\mathrm{Hg}$ onto HGR-AC and the kinetics of this sorption process, mass transfer processes within the carbon-filled cylinder can be added to the theoretical uptake model. ${ }^{33}$ It is anticipated that additional measurements and an expanded model will lead to an improved understanding of the trends in the SR that might occur during shorter deployments.

\section{ASSOCIATED CONTENT}

\section{S Supporting Information}

The Supporting Information is available free of charge on the ACS Publications website at DOI: 10.1021/acs.estlett.5b00319.

Detailed description of experimental methodologies, determination of SRs, and the actively measured gaseous $\mathrm{Hg}$ concentrations for each separate deployment period (PDF)

\section{AUTHOR INFORMATION}

\section{Corresponding Author}

*E-mail: frank.wania@utoronto.ca. Phone: +1-416-287-7225.

\section{Notes}

The authors declare no competing financial interest.

\section{ACKNOWLEDGMENTS}

We acknowledge funding from Environment Canada and a Strategic Project Grant of the Natural Sciences and Engineering Research Council of Canada. We thank John Ford and his colleagues from the chemistry machine shop for their contribution to designing and building the PAS and Calgon Carbon for donating the activated carbon samples.

\section{REFERENCES}

(1) Driscoll, C. T.; Mason, R. P.; Chan, H. M.; Jacob, D. J.; Pirrone, N. Mercury as a global pollutant: sources, pathways, and effects. Environ. Sci. Technol. 2013, 47, 4967-4983.

(2) Pirrone, N.; et al. Global mercury emissions to the atmosphere from anthropogenic and natural sources. Atmos. Chem. Phys. 2010, 10, 5951-5964.

(3) Selin, N. E. Global biogeochemical cycling of mercury: a review. Annu. Rev. Env. Resour. 2009, 34, 43-63.

(4) Lin, C.-J.; Pongprueksa, P.; Lindberg, S. E.; Pehkonen, S. O.; Byun, D.; Jang, C. Scientific uncertainties in atmospheric mercury models I: model science evaluation. Atmos. Environ. 2006, 40, 29112928.

(5) Skov, H.; Christensen, J. H.; Goodsite, M. E.; Heidam, N. Z.; Jensen, B.; Wåhlin, P.; Geernaert, G. Fate of elemental mercury in the Arctic during atmospheric mercury depletion episodes and the load of atmospheric mercury to the Arctic. Environ. Sci. Technol. 2004, 38, $2373-2382$.

(6) Rutter, A. P.; Snyder, D. C.; Stone, E. A.; Schauer, J. J.; GonzalezAbraham, R.; Molina, L. T.; Márquez, C.; Cárdenas, B.; de Foy, B. In situ measurements of speciated atmospheric mercury and the identification of source regions in the Mexico City Metropolitan Area. Atmos. Chem. Phys. 2009, 9, 207-220.

(7) Peterson, C.; Gustin, M.; Lyman, S. Atmospheric mercury concentrations and speciation measured from 2004 to 2007 in Reno, Nevada, USA. Atmos. Environ. 2009, 43, 4646-4654.

(8) Gauchard, P.-A.; Aspmo, K.; Temme, C.; Steffen, A.; Ferrari, C.; Berg, T.; Ström, J.; Kaleschke, L.; Dommergue, A.; Bahlmann, E.; Magand, O.; Planchon, F.; Ebinghaus, R.; Banic, C.; Nagorski, S.; Baussand, P.; Boutron, C. Study of the origin of atmospheric mercury depletion events recorded in Ny-Ålesund, Svalbard, spring 2003. Atmos. Environ. 2005, 39, 7620-7632.

(9) Gustin, M.; Amos, H.; Huang, J.; Miller, M.; Heidecorn, K. Measuring and modeling mercury in the atmosphere: a critical review. Atmos. Chem. Phys. 2015, 15, 5697-5713.

(10) Gustin, M. S.; Lyman, S. N.; Kilner, P.; Prestbo, E. Development of a passive sampler for gaseous mercury. Atmos. Environ. 2011, 45, $5805-5812$

(11) Pirrone, N.; Aas, W.; Cinnirella, S.; Ebinghaus, R.; Hedgecock, I. M.; Pacyna, J.; Sprovieri, F.; Sunderland, E. M. Toward the next generation of air quality monitoring: mercury. Atmos. Environ. 2013, $80,599-611$.

(12) Brown, R. J.; Goddard, S. L.; Butterfield, D. M.; Brown, A. S.; Robins, C.; Mustoe, C. L.; McGhee, E. A. Ten years of mercury measurement at urban and industrial air quality monitoring stations in the UK. Atmos. Environ. 2015, 109, 1-8.

(13) Zhu, J.; Wang, T.; Talbot, R.; Mao, H.; Hall, C.; Yang, X.; Fu, C.; Zhuang, B.; Li, S.; Han, Y.; Huang, X. Characteristics of atmospheric total gaseous mercury (TGM) observed in urban Nanjing, China. Atmos. Chem. Phys. 2012, 12, 12103-12118.

(14) Huang, J.; Liu, C.-K.; Huang, C.-S.; Fang, G.-C. Atmospheric mercury pollution at an urban site in central Taiwan: Mercury emission sources at ground level. Chemosphere 2012, 87, 579-585.

(15) McLagan, D. S.; Mazur, M. E. E.; Mitchell, C. P. J.; Wania, F. Passive air sampling of gaseous elemental mercury: a critical review. Atmos. Chem. Phys. Discuss. 2015, 15, 34605-34645.

(16) Minamata Convention on Mercury: Text and Annexes; United Nations Environmental Programme: Geneva, 2013; p 67. 
(17) Gustin, M.; Jaffe, D. Reducing the uncertainty in measurement and understanding of mercury in the atmosphere. Environ. Sci. Technol. 2010, 44, 2222-2227.

(18) Huang, J.; Lyman, S. N.; Hartman, J. S.; Gustin, M. S. A review of passive sampling systems for ambient air mercury measurements. Environ. Sci. Process. Impacts 2014, 16, 374-392.

(19) Zhang, W.; Tong, Y.; Hu, D.; Ou, L.; Wang, X. Characterization of atmospheric mercury concentrations along an urban-rural gradient using a newly developed passive sampler. Atmos. Environ. 2012, 47, $26-32$.

(20) Skov, H.; Sørensen, B. T.; Landis, M. S.; Johnson, M. S.; Sacco, P.; Goodsite, M. E.; Lohse, C.; Christiansen, K. S. Performance of a new diffusive sampler for $\mathrm{Hg} 0$ determination in the troposphere. Environ. Chem. 2007, 4, 75-80.

(21) Cole, A. S.; Steffen, A. Trends in long-term gaseous mercury observations in the Arctic and effects of temperature and other atmospheric conditions. Atmos. Chem. Phys. 2010, 10, 4661-4672.

(22) Method 7473: Mercury in solids and solutions by thermal decomposition, amalgamation, and atomic absorption spectrophotometry; U.S. Environmental Protection Agency: Washington, DC, 2007; p 17.

(23) Restrepo, A. R.; Hayward, S. J.; Armitage, J. M.; Wania, F. Evaluating the PAS-SIM model using a passive air sampler calibration study for pesticides. Environ. Sci. Process. Impacts 2015, 17, 1228-1237.

(24) Mackay, D. Multimedia Environmental Models: The Fugacity Approach, 2nd ed.; CRC Press: Boca Raton, FL, 2001.

(25) Brown, R. J. C.; Burdon, M. K.; Brown, A. S.; Kim, K.-H. Assessment of pumped mercury vapour adsorption tubes as passive samplers using a micro-exposure chamber. J. Environ. Monit. 2012, 14, 2456-2463.

(26) Huang, J.; Choi, H.-D.; Landis, M. S.; Holsen, T. M. An application of passive samplers to understand atmospheric mercury concentration and dry deposition spatial distributions. J. Environ. Monit. 2012, 14, 2976-2982.

(27) Pennequin-Cardinal, A.; Plaisance, H.; Locoge, N.; Ramalho, O.; Kirchner, S.; Galloo, J.-C. Performances of the Radiello ${ }^{\circledR}$ diffusive sampler for BTEX measurements: Influence of environmental conditions and determination of modelled sampling rates. Atmos. Environ. 2005, 39, 2535-2544.

(28) Plaisance, H.; Sagnier, I.; Saison, J.; Galloo, J.; Guillermo, R. Performances and application of a passive sampling method for the simultaneous determination of nitrogen dioxide and sulfur dioxide in ambient air. Environ. Monit. Assess. 2002, 79, 301-315.

(29) Zhang, X.; Brown, T. N.; Ansari, A.; Yeun, B.; Kitaoka, K.; Kondo, A.; Lei, Y. D.; Wania, F. Effect of wind on the chemical uptake kinetics of a passive air sampler. Environ. Sci. Technol. 2013, 47, 78687875 .

(30) Temme, C.; Blanchard, P.; Steffen, A.; Banic, C.; Beauchamp, S.; Poissant, L.; Tordon, R.; Wiens, B. Trend, seasonal and multivariate analysis study of total gaseous mercury data from the Canadian atmospheric mercury measurement network (CAMNet). Atmos. Environ. 2007, 41, 5423-5441.

(31) Chaemfa, C.; Barber, J. L.; Gocht, T.; Harner, T.; Holoubek, I.; Klanova, J.; Jones, K. C. Field calibration of polyurethane foam (PUF) disk passive air samplers for PCBs and OC pesticides. Environ. Pollut. 2008, 156, 1290-1297.

(32) Tsurukawa, M.; Suzuki, M.; Okuno, T.; Takemine, S.; Okada, Y.; Matsumura, C.; Nakano, T. Calibration and field survey of passive air samplers for persistent organic pollutants. Organohalogen Compd. 2010, 72, 884-887.

(33) Zhang, X.; Wania, F. Modeling the uptake of semivolatile organic compounds by passive air samplers: Importance of mass transfer processes within the porous sampling media. Environ. Sci. Technol. 2012, 46, 9563-9570.

(34) Vidic, R. D.; Chang, M.-T.; Thurnau, R. C. Kinetics of vaporphase mercury uptake by virgin and sulfur-impregnated activated carbons. J. Air Waste Manage. Assoc. 1998, 48, 247-255.

(35) Armitage, J. M.; Hayward, S. J.; Wania, F. Modeling the uptake of neutral organic chemicals on XAD passive air samplers under variable temperatures, external wind speeds and ambient air concentrations (PAS-SIM). Environ. Sci. Technol. 2013, 47, 1354613554 .

(36) Massman, W. Molecular diffusivities of $\mathrm{Hg}$ vapor in air, $\mathrm{O}_{2}$ and $\mathrm{N}_{2}$ near STP and the kinematic viscosity and thermal diffusivity of air near STP. Atmos. Environ. 1999, 33, 453-457. 